\title{
Bankalara Olan Borçlarını Yeniden Yapılandıran Firmaların Başarısında, Banka Kredilerine Erişim Yeteneğinin ve Finansal Başarısızlık Derecesinin Etkisi
}

The Effcet of the Abilty to Access to Bank Credit and the Complexity of the Financial Distress in the Process of Successfully Dept Restructuring Firms

\author{
Selçuk KAPLAN \\ Dr.TC Ziraat Bankası Şube Yöneticisi, (skaplan@ziraatbank.com.tr)
}

\begin{abstract}
ÖZET
Anahtar kelimeler: $\quad$ Çalışmada, özel görüşme yoluyla banka borçlarını yapılandıran 109 firmanın başarılı borç yapılanmasında, bankanın katkısı ve sorun karmașasının etkisi irdelenmiştir. Banka katkısı TCMB verilerinden sağlanan limit

Finansal Sikıntı

Finansal doluluk oranı ile sorun karmaşası ise faiz ödeme performansı ile ölçülmüşürr. Başarısı firmalarda dış

Yapılandirma fonlara erişim yeteneği kısıtlanırken, sorun karmaşası artmaktadır. Geliştirilen lojistik modelde, yapılanma Borç Yapılandırması öncesi dönemde ve yapılanma döneminde dış fonlara erişim yeteneğinin, başarılı borç yapılanmasında önemli olduğu ortaya çıkmıştır.
\end{abstract}

\author{
Keywords: \\ Financial Distress \\ Financial \\ Restructuring \\ Dept Restructuring
}

\begin{abstract}
In this study, the bank contribution and the effect of the complexty of the financial distress were inversigated in the proses of sucsesfully dept restructurig of totally 109 firms that restructure their bankdept by the means of out of court resolution. Bank contribution to the proses is represented by ratio of credit line fulness, the data extracted from TCMB resource, and the complexty of the problem are measured by interest payment performans of the firms. While the failure firms' abilty to use credit line was limited,the complexty of the trouble was increased.In the logit model, It is important to use creditline for the seccessful firms in terms of competing deptrestructuring.
\end{abstract}

\section{GİRIŞ}

Firmaların aşırı kaldıraç kullanmaları (özellikle ABD'de 1980' lerden sonra high-yield bond veya junk bonds borçlanmalarının yaygın olarak kullanılması) borçlarını ödeyememe potansiyelini artırmışıı. Bu türden finansal yapıya sahip firmaların, finansal başarısızlık sorunu ile nasıl başa çıkacaklarının anlaşılması konusu ekonomistlerin, yöneticilerin ve akademisyenlerin ilgisini çekmiştir. (Hotchkiss, 2008: 3)

Problemin tanımlanmasına yönelik olarak, Tablo-1 de Gartner and Scharfstein (1991) in özel görüşme yoluyla borç yapılanmasına kuramsal yaklaşımının özet bir sunumu bulunmaktadır.

Finansal başarısızlık sorunsalı, ödemenin aksatıldığı noktada başlayan (zaman1), firmanın sorunu çözümlediği noktada (zaman2) sona eren bir zaman aralığında irdelenmektedir. Finansal yönden başarısız firma bu süre aralığında, yeniden yapılanma yapmakta ve yeni yatırım olanaklarını değerlendirmektedir. Kuramsal analizde kısa vadeli borçlar ve Banka 
borçlarının zaman1 noktasında ödeneceği, zaman 2 noktasında ise yatırımın nakit akışının oluşacağı ve Uzun Süreli Borçların ödeneceği varsayılmaktadır. Genel olarak firma üzerinde hak talep eden üç grup düşünülmektedir: Firma sahibi ve adına hareket eden yönetici, davranışlarını koordine edemeyen dağınık yapıdaki alacaklı grubu ve borçluyu izleme araçlarına sahip ve borçlu ile sorunu müzakere edebilen banka gibi kurumsal alacaklı. Taraflar, firmanın finansal yükümlülüklerini yerine getiremediği zaman 1 noktasında, mevcut ve gelecekteki firma değeri ile finansal haklarının mevcut durumu üzerinden, firmanın yeniden yapılanmasına kararını etkinlik açısından değerlendirmekte ve karar kriterini bu merkezde oluşturmaktadır.

Tablo-1: Finansal Sıkıntı Tanımlanması ve Banka Borçlarının Yapılandırılmasına Kuramsal Yaklaşım

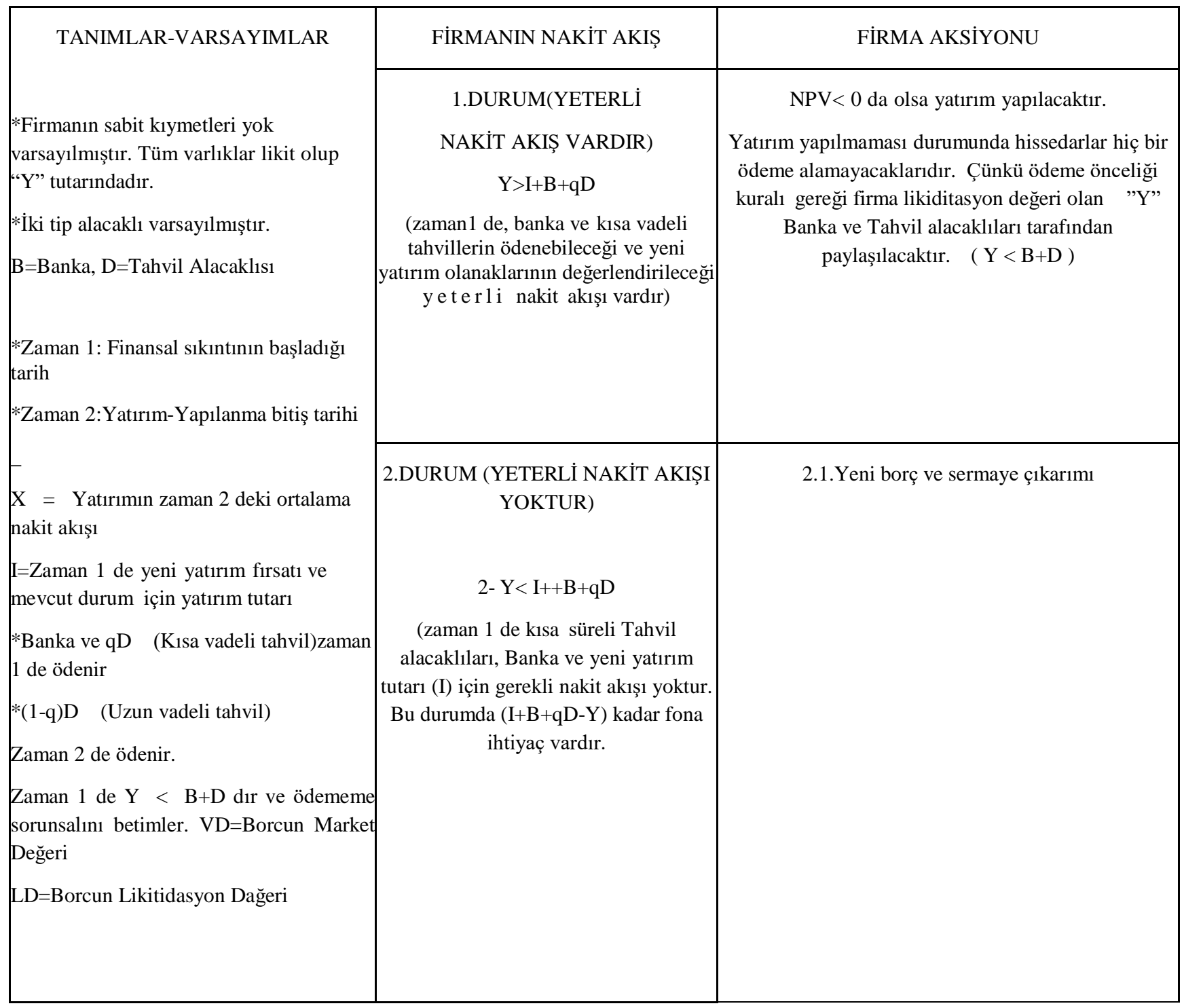




\begin{tabular}{|c|c|c|}
\hline $\begin{array}{l}\text { BANKA BORÇLARININ } \\
\text { YAPILANDIRILMASI } \\
\text { KRITERİ: }\end{array}$ & \begin{tabular}{|c|} 
VD-D>0,yatırımın yapılması \\
durumunda borç değerindeki artışı \\
ifade eder. Bu tahvil alacaklılarına \\
transfer anlamındadır. \\
X-I(NPV) $=>$ VD-VL olması \\
durumunda yatırım yapılacaktır. Çünkü \\
alacaklılara yapılan transfer den büyük \\
nakit akış1, hissedarları yatırım için \\
özendirecektir.
\end{tabular} & 2.2.Banka ve Tahvil Borçlarının yapılandırılması \\
\hline
\end{tabular}

Kaynak: Robert Gartner and David Scharfstein(1991) "A Theory of Workouts and the Effects of Reorganization Law,The journal of Finance, Vol,46,S:1189-1196

Borç yapılanması, firmanın finansal yükümlülüklerini yerine getiremediği bir noktada, default durumundan kaçınmak için, var olan borç sözleşmelerinin yenileri ile değiştirildiği bir "işlemler" bütünü olarak tanımlamakta ve bu işlemler üç başlık altında toplanmaktadır. (Gilson vd, 1990: 325)
i) Anapara faiz ödemelerinde indirim
ii) Vade zatımı
iii) Kreditörlere belirli bir ödeme yapmak yerine hisse senedi verilmesi

Benzer şekilde, Hotchkiss vd (2008) de, firmanın kaynak yapısının, uyulmaması halinde firmayı yasal yaptırımlarla karşılaştıracak sözleşmeler (hard contract) ve kar payı ödemesi gibi yaptırımı oransal olarak daha hafif (soft kontract) oluştuğunu belirterek, borç yapılanmasını, eski borç sözleşmelerinin, vade, anapara, faiz gibi unsurlarının firmanın nakit akışına uygun bir şekilde yenileri ile değiştirmek olarak tanımlamıştır.(Hotchkiss vd, 2008:15)

Finansal başarısızlığın çözümü, firmanın kısa dönem nakit akışının iyileştirilmesi, diğer bir anlatımla borç baskısının hafifletilmesiyle olanaklı bulunmaktadır. Bu bağlamda finansal açıdan sıkıntılı firma, bilançosunu dışsal bir etki ile (kreditörün baskısı) düzenlemek zorundadır.

Çalışmamız finansal sıkıntıyı aşma amacıyla var olan banka borçlarını yapılandırmak isteyen firmaların, başarılı borç yapılanmasında, bankanın katkısının ve firmanın içinde bulunduğu sıkıntı derecenin önemli olup olmadığını araştırmaya yöneliktir.

\section{BORÇ YAPILANMASINA ETKI DEĞISSKENLERIN BELİRLENMESINE YÖNELIK DAHA ÖNCE YAPILMIŞ ÇALIŞMALAR}

Araştırmamız, finansal açıdan başarısız firmalarda, yapılanma öncesi dönemde ve yapılanma döneminde, bankanın sürece katkısının ve finansal sıkıntının şiddetinin etkisini araştırmaktadır.

Her bir değişkenin başarılı borç yapılanması ile ilişkisini ortaya koymaya yönelik daha önce yapılan araştırmalar aşağıda iki ayrı başlık altında sunulmuştur. 


\subsection{Başarılı Borç Yapılanmasında Bankanın Rolü İli İlgili Daha Önce Yapılmış Çalışmalar}

Yazında, borç yapılanmasında, bankanın etkisini irdeleyen çalışmaların özet sonuçları Tablo -2 de verilmiştir.

Genel hatları ile bakıldığında, literatürde, bankaların gerek yasal yönden baskı altında olmalarının etkisiyle taviz vermez tutumları, gerekse alacaklarının teminatlı olması nedeniyle, ((Asquit vd (1991), Gilson (1997)) borç yapılanmalarına katkılarının sınırlı olduğu yönünde görüşler bulunmaktadır.

Diğer yandan yazında, yukarıdaki görüşün aksine, bankaların, direnme (hold out) ve asimetrik bilgi sorununu azaltması nedeniyle, sürece pozitif katkısının olduğu belirten araştırmalar da bulunmaktadır. ((Brown vd (1993), James(1996), Gilson,John ve Lang (1990), Ofek (1993), Gilson (1997))

Çalı̧̧mamızda, bankanın katılımının apriori olarak başarılı borç yapılanmasında olumlu katkı sunacağı kabul edilmiştir.

Tablo-2: Borç Yapılanmasında Bankanın Rolüne İliş̧kin Bazı çalışmaların Özet Sonuçları

\begin{tabular}{|c|c|c|}
\hline YAZAR & ÇALIŞMA ÖRNEKLEMİ & ÇALIŞMA SONUCU \\
\hline Asquit vd (1991) & $\begin{array}{l}\text { 1970-1980 yıllarında, yüksek kaldıraç } \\
\text { kullanan102 firma. (Firmaların } \\
\text { tümünün borç yapısında yüksek } \\
\text { getirili tahvil bulunmaktadır.) }\end{array}$ & $\begin{array}{l}\text {-Finansal sıkıntının yüksek bir maliyet içermemesi halinde } \\
\text { bankalar borç yapılanmasına yatkındırlar. } \\
\text {-Borç yapılanması genellikle, sözleşme koşullarının yenilenmesi } \\
\text { şeklinde (vade uzatımı gibi) olmaktadır. Anaparadan vazgeçme } \\
\text { nadirdir. } \\
\text {-Mevcut ve gelecekteki performansı iyi olan firmalara daha } \\
\text { tölaranslı davranılmaktadır. } \\
\text {-Bankanın katkısı alacağın tahsili bakımından düşük öncelikli tahvil } \\
\text { alacaklısına yarar sağlayacağından banka anaparadan vazgeçme, } \\
\text { yeni finansman sağlama gibi araçları kullanmaya isteksizdir. } \\
\text {-Alacakları teminatlı olan banka yasal süreç altında yapılanmaya } \\
\text { eğilimlidir. }\end{array}$ \\
\hline Brown vd (1993) & $\begin{array}{l}\text { 1980-1990 yıllarında, banka ve } \\
\text { tahvil yapılanması yapan } 70 \text { firma }\end{array}$ & $\begin{array}{l}\text { Bankanın düşük ödeme önceliği olan öneri (borç yerine sermaye) } \\
\text { önerilmesi durumunda, bunun firmanın gelecekteki durumu } \\
\text { hakkında olumlu bir bilgi içermesi nedeniyle, firma hisselerinde } \\
\% 9,13 \text { artış olduğu görülmüştür. Bankanın, firma hakkında iyi } \\
\text { düzeyde bilgi sahibi olduğu göz önüne alındığında, başarılı borç } \\
\text { yapılanmasında, bankanın katılımının ve rolünün önemli olduğu } \\
\text { ortaya konmuştur. }\end{array}$ \\
\hline
\end{tabular}




\begin{tabular}{|c|c|c|}
\hline James(1996) & $\begin{array}{c}\text { 1980-1990 yılları arasında tahvil } \\
\text { alacaklıları (Exchange offer) ve } \\
\text { bankalar ile yapılanma yapan } 68 \text { halka } \\
\text { açık şirket }\end{array}$ & $\begin{array}{l}\text {-Operasyonel performansı ve borç düzeyi exante kötü olan } \\
\text { firmalarda borç indirimi daha fazladır. } \\
\text {-Toplam borç yapısında banka payı artıkça, ( başarısız yapılanmada } \\
\text { bankanın zararı artacağından) bankanın yapılanmaya bir taviz ile } \\
\text { katılma isteği artacaktır. } \\
\text {-Bankanın katılımı direnme (hold out) ve asimetrik bilgi sorununu } \\
\text { azaltır. } \\
\text {-Yasal süreç dışında borç yapılanmasında bankanın önemli bir } \\
\text { rolü bulunmaktadır. }\end{array}$ \\
\hline $\begin{array}{l}\text { Gilson, John ve } \\
\text { Lang (1990) }\end{array}$ & $\begin{array}{l}\text { 1978-1987 yılları arasında ödeme } \\
\text { sorunu yaşayan } 169 \text { halka açık şirket }\end{array}$ & $\begin{array}{l}\text { Sıkıntılı firmaların yasal süreç(bölüm 11) ya da özel görüşme } \\
\text { yoluyla yapılanmasının belirleyicilerini araştıran yazarlar, özel } \\
\text { görüşme yoluyla borç yapılanmasında borç yapısının etkisi üzerinde } \\
\text { durmuşlardır. Banka ağırlıklı ya da az sayıda alacaklının olduğu } \\
\text { firmalarda, özel görüşme yoluyla başarılı borç yapılanma şansının } \\
\text { daha yüksek olduğu bulgulamışlardır. } \\
\text { Özet olarak, yasal süreç dışında borç yapılanmasında, borç } \\
\text { bileşiminde daha çok banka borcu olan firmalarda direnme (hold } \\
\text { out) azalmakta, bu ise yapıllanmanın başarı şansının artırmaktadır. }\end{array}$ \\
\hline Ofek (1993) & $\begin{array}{c}\text { 1983-1987 yılları arasında şok } \\
\text { performans düşüşü yaşayan } 358 \text { firma }\end{array}$ & $\begin{array}{l}\text { Araştırmada, kısa süreli finansal sıkıntı sürecinde, firma tepkisi ile } \\
\text { sermaye yapısı arasındaki ilişki irdelenmiştir. Yapısında banka gibi } \\
\text { kurumsal alacaklının yoğun olduğu firmaların, özel görüşme ile borç } \\
\text { yapılanma yapma ihtimali artırmaktadır. }\end{array}$ \\
\hline Gilson (1997) & $\begin{array}{c}\text { 1979-1989 yılları arasında, 51 ‘i yasal } \\
\text { süreç altında (bölüm11), 57’si yasal } \\
\text { süreç dışında borç yapılanması yapan } \\
108 \text { halka açık şirket }\end{array}$ & $\begin{array}{l}\text { Yapılan çalışmada, yasal süreç dışında borç yapılanması yapan } \\
\text { firmalarda, daha az banka borcu ve daha az kurumsal alacaklı } \\
\text { sayısına sahip firmalarda, borç düzeyinin daha çok azaldığı } \\
\text { gözlenmiştir. Yani, bankalar yapılanma döneminde borç düzeyini } \\
\text { azaltacak yapılanma anlaşmalarına pek yanaşmamaktadırlar. } \\
\text { Yasal süreç yapılanmasında, borç yapısının (banka ağırlıklı-değil) } \\
\text { borç azalmasında (bankaların taviz verip vermediği konusu } \\
\text { irdelenmiştir) önemli olmadığı ortaya çıkmıştır. Araştırmacı, bunu; } \\
\text { yasal sürecin zorlayıcı yapısına ve direnmenin giderilmesine } \\
\text { bağlamıştır. }\end{array}$ \\
\hline
\end{tabular}




\subsection{Başarılı Borç Yapılanmasında Finansal başarısızlık Derecesinin Etkisi İle İIgili Daha Önce Yapılmış Çalışmalar}

Finansal başarısızlık, geçici likidite sıkıntısından, iflas sürecine kadar uzanan şiddette ortaya çıkabilmektedir. Finansal sıkıntının şiddeti artıkça, uzlaşma zemini kayıp olmakta ve taraflar, firmanın yaşamasına devam edecek reorganizasyonun yasal bir çatı altında yapılması yolunu seçmektedir. Tablo -3 de, firmada sıkıntı boyutunu belirleyen direnme ve asitmetrik bilgi akışının, yapılanma türü (yasal süreç-mahkeme gözetiminde yapılanma- ya da özel görüşme yoluyla -mahkeme dış1)seçimi arasındaki ilişkileri irdeleyen çalışmalar verilmektedir. Genel olarak bakıldığında bu çalışmalardan aşağıdaki sonuçları çıkarmak olasıdır.

i)Banka gibi kurumsal alacaklıların ağılıklı olduğu firmalarda, direnme ve asimetrik bilgi akışı azalmakta ve yasal süreç dişı yapılanma tercih edilmektedir.

ii)Asimetrik bilgi akışı firmaları yasal süreç altında yapılanmaya yöneltmektedir.

iii)Yasal süreç maliyetlidir ve firmanın rehabilitesi uzun zaman alır.

Çalışmamızda bu kuramsal beklentiye uygun olarak, finansal açıdan başarısız firmaların sorun karmaşası (hangi değişkenlerle proxy edildiği”" Araştırma Yöntem ve Bulguları" bölümünde verilmiştir) artıkça, başarılı bir borç yapılanma ihtimalinin azalacağ 1 varsayılmıştır.

Tablo 3 : Yapılanma Türü ile Finansal Başarısızlık Sorunu Arasındaki İlişkileri İrdeleyen Bazı Çalışmaların Özet sonuçları

\begin{tabular}{|c|c|c|}
\hline $\begin{array}{l}\text { ÇALIŞMANIN } \\
\text { KONUSU }\end{array}$ & ÇALIŞMAYI YAPAN & AÇIKLAMA \\
\hline \multirow[t]{2}{*}{ SÜRE VE MALIYYT } & $\begin{array}{l}\text { Gilson, John ve Lang } \\
\text { (1990) }\end{array}$ & $\begin{array}{l}\text {-Yasal süreç altında borç yapılanması daha uzun zaman ve } \\
\text { maliyet içermektedir }\end{array}$ \\
\hline & $\begin{array}{l}\text { Franks ve Torous } \\
\qquad(1994)\end{array}$ & -Yasal süreç yapılanmasında geçen süre daha uzundur \\
\hline \multirow[t]{2}{*}{$\begin{array}{l}\text { SORUNUN } \\
\text { KARMAŞIKLIĞI VE } \\
\text { DIRENME }\end{array}$} & $\begin{array}{l}\text { Gilson, John ve Lang } \\
\text { (1990) }\end{array}$ & $\begin{array}{l}\text {-Tahvil ağırlıkı borç yapısı (kurumsal alacaklının az olduğu) } \\
\text { direnmeyi artırır. } \\
\text {-Direnmenin artması, firmaları uzlaşı için yasal süreçte } \\
\text { yapılanmaya zorlar. }\end{array}$ \\
\hline & $\begin{array}{l}\text { Franks ve Torous } \\
\qquad(1994)\end{array}$ & $\begin{array}{l}\text {-Karmaşıklık düzeyi ile yapılanma türü arasında ilişki } \\
\text { bulunamamıştır. (Kuramsal beklentinin tersine gelişen bu durumun } \\
\text { örneklem seçiminden olabileceği belirtilmiştir) }\end{array}$ \\
\hline
\end{tabular}




\begin{tabular}{|c|c|c|}
\hline & Ofek (1993) & $\begin{array}{l}\text {-Yapısında banka gibi kurumsal alacaklının yoğun olduğu } \\
\text { firmaların, özel görüşme ile yapılanma yapma ihtimalini } \\
\text { artırmaktadır. }\end{array}$ \\
\hline \multirow[t]{3}{*}{$\begin{array}{l}\text { ASIMETRIKK } \\
\text { BİLGI }\end{array}$} & $\begin{array}{l}\text { Gilso, John ve Lang } \\
\text { (1990) }\end{array}$ & $\begin{array}{l}\text {-Asimetrik bilgi firmaları yasal süreç altında yapılanmaya } \\
\text { itmektedir. }\end{array}$ \\
\hline & $\begin{array}{l}\text { Mooradian (1994) } \\
\text { ( Teorik çalışma ) }\end{array}$ & $\begin{array}{l}\text { Yasal süreçte yapılanma (Bölüm 11) bilgi asimetrisi sorununu } \\
\text { azaltır. }\end{array}$ \\
\hline & Asquit vd (1991) & $\begin{array}{l}\text { Banka ağırlıklı borç yapısına sahip firmalarda, uzlaşarak çözüm } \\
\text { güçleşir, Çünkü banka gibi kurumsal alacaklılar, teminat yapısı da } \\
\text { gözetilerek taviz vermeye yanaşmazlar. }\end{array}$ \\
\hline
\end{tabular}

\section{ARAŞTIRMANIN YÖNTEM VE BULGULARI}

\section{1.Örneklem Seçimi}

Örneklem, bir Kamu Bankasında vadesi geçmiş veya vadesi gelmediği halde bu tarihten önce, banka ile özel görüşme yapmak suretiyle, borçlarının vadelerini uzatmış veya yapılandırmış(bir ödeme planına bağlı olarak tasfiyeyi amaçlayan), likidite yetersizliği hafif şiddette olan, etkinliğine devam eden ve alacaklıların yasal süreç başlatmadığı firmalardan oluşmaktadır. Örnekleme, bu kriterleri taşıyan, 44` ü başarılı, 65’ ' başarısız borç yapılanması yapmış toplam 109 firma dahil edilmiştir.

İlgili Banka Genel Müdürlüğünden, firma isimlerinin veya firmaların kullandı̆̆g logo ve kısaltmaların kullanılmaması koşulu ile firma verilerinin kullanılabilmesi için izin alınmıştır. Belirtilen, yasal zorunluluk nedeniyle, araştırmada firma isimleri kullanılmamış, bunun yerine Firma 1, Firma 2 gibi isimlendirmeler yapılmıştır. Veriler, TCMB nın bankaların erişimine izin verdiği, limit ve risk bilgilerinden edinilmiştir.

\subsection{Araştırma Modeli ve Değişkenler}

Çalışmamızda başarılı borç yapılanmasında alacaklı bankaların sürece katkısını ve finansal sıkıntı şiddetinin etkisini ölçmek için lojistik regresyon modeli uygulanmış ve aşağıdaki gibi kurgulanmıştır.

$\mathrm{L}=\mathrm{bo}+\mathrm{b} 1 \mathrm{~A} 11+\mathrm{b} 2 \mathrm{~A} 12+\mathrm{b} 3 \mathrm{~A} 31+\mathrm{b} 4 \mathrm{~A} 32+\mathrm{b} 5 \mathrm{~A} 41+\mathrm{b} 6 \mathrm{~A} 42+\mathrm{e}$ dir.

\subsubsection{Bağımlı Değişken}

Modelde, bağımlı değişken olarak firmaların başarı durumları alınmıştır:

(başarılı firma $=1$, başarısız firma $=0$ )

Borçlarını yeni sözleşme koşullarına bağlayan firmalardan, borcunu belirlenen yeni vadede ödeyen, ödeme planına uyarak bankanın kabul ettiği ölçüde kısmen ödeyen firmalar BAŞARILI, ödeme planına uymayarak borçlarını ikinci kez yapılandıran veya yasal sürecin başlatılması yönünde aksiyon alınan firmalar BAŞARISIZ olarak kabul edilmiştir. 


\subsubsection{Bağımsız Değiş̧kenler}

Tablo-4: Modeldeki Bağımsız Değişkenler

\begin{tabular}{|c|c|c|c|c|}
\hline $\begin{array}{l}\text { DEĞİŞKENIN } \\
\text { ÖLÇTÜĞÜ }\end{array}$ & KODU & ADI & HESAPLAMASI & AÇIKLAMA \\
\hline $\begin{array}{l}\text { DIŞ FONLARA ERIŞ̧İM } \\
\text { YETENEĞİ }\end{array}$ & A11 & $\begin{array}{l}\text { YAPILANMA } \\
\text { ÖNCESİ LIMİT } \\
\text { DOLULUK ORANI }\end{array}$ & ORTALAMA RİSK/LIMIIT & $\begin{array}{l}\text { Bankalardaki kullanılabilir limit } \\
\text { boşluğunu gösterir. Yüksek oran dış } \\
\text { fonlara erişimin kısıtlandığını gösterir. }\end{array}$ \\
\hline $\begin{array}{l}\text { DIŞ FONLARA ERIŞ̧IM } \\
\text { YETENEĞİ }\end{array}$ & A12 & $\begin{array}{l}\text { YAPILANMA } \\
\text { DÖNEMİ LIMITT } \\
\text { DOLULUK ORANI }\end{array}$ & ORTALAMA RİSK/LİMİT & $\begin{array}{l}\text { Bankalardaki kullanılabilir limit } \\
\text { boşluğunu gösterir. Yüksek oran dış } \\
\text { fonlara erişimin kısıtlandığını gösterir. }\end{array}$ \\
\hline $\begin{array}{l}\text { SORUN KARMAŞASI- } \\
\text { SIKINTI ŞİDDETİ }\end{array}$ & A31 & $\begin{array}{l}\text { YAPILANMA } \\
\text { ÖNCESİ FAİZ } \\
\text { ÖDEME } \\
\text { PERFORMANSI }\end{array}$ & $\begin{array}{l}\text { ORTALAMA } \\
\text { ÖDENMEMIŞ } \\
\text { FAİZ/ORTALAMA } \\
\text { BANKA BORCU }\end{array}$ & $\begin{array}{l}\text { Ödenmeyen faiz boyutunu gösterir. } \\
\text { Oran büyüdükçe sorun karmaşası artar }\end{array}$ \\
\hline $\begin{array}{l}\text { SORUN KARMAŞASI- } \\
\text { SIKINTI ŞIDDDTI }\end{array}$ & A32 & $\begin{array}{l}\text { YAPILANMA } \\
\text { DÖNEMİ FAIZ } \\
\text { ÖDEME } \\
\text { PERFORMANSI }\end{array}$ & $\begin{array}{l}\text { ORTALAMA } \\
\text { ÖDENMEMİŞ } \\
\text { FAİZ/ORTALAMA } \\
\text { BANKA BORCU }\end{array}$ & $\begin{array}{l}\text { Ödenmeyen faiz boyutunu gösterir. } \\
\text { Oran büyüdükçe sorun karmaşası } \\
\text { artar. }\end{array}$ \\
\hline $\begin{array}{l}\text { SORUN KARMAŞASI- } \\
\text { SIKINTI ŞIDDETI }\end{array}$ & A41 & $\begin{array}{l}\text { YAPILANMA } \\
\text { ÖNCESİ FAİZ } \\
\text { ÖDEME } \\
\text { PERFORMANSI }\end{array}$ & $\begin{array}{l}\text { ÖDENMEMİŞ DÖNEM } \\
\text { SAYISI/ TOPLAM } \\
\text { DÖNEM SAYISI(12) }\end{array}$ & $\begin{array}{l}\text { Ödenmeyen faiz boyutunu gösterir. } \\
\text { Oran büyüdükçe sorun karmaşası artar }\end{array}$ \\
\hline $\begin{array}{l}\text { SORUN KARMAŞASI- } \\
\text { SIKINTI ŞIDDETI }\end{array}$ & A42 & $\begin{array}{l}\text { YAPILANMA } \\
\text { DÖNEMİ FAİZ } \\
\text { ÖDEME } \\
\text { PERFORMANSI }\end{array}$ & $\begin{array}{l}\text { ÖDENMEMİŞ BORÇ/ } \\
\text { ORTALAMA SATIŞ }\end{array}$ & $\begin{array}{l}\text { Ödenmeyen faiz boyutunu gösterir. } \\
\text { Oran büyüdükçe sorun karmaşası artar }\end{array}$ \\
\hline
\end{tabular}

Modelde, değişkenler hem yapılanma öncesinde hem de yapılanma döneminde ayrı ayrı ölçülmüştür. Burada, "Yapılanma Öncesi Dönem “ firmanın yapılanma yaptığı tarihten önceki 12 aylık dönemi ifade etmektedir.

“Yapılanma Dönemi “ ise, vade uzatımı yapılmış veya ödeme planına bağlanmış alacaklarda, yapılanmanın yapıldığı tarih ile ödemenin yapıldığı tarih arasındaki süredir. Yapılanma süreci devam eden, ancak yeterli düzeyde ödeme yaptığı için başarılı ödeme yaptığı kabul edilen firmalar için yapılanma dönemi, yapılanmanın yapıldığı tarih ile inceleme dönemi arasındaki 
süre olarak tanımlanmıştır. Başarısız yapılanmalarda ise, yapılanmanın yapıldığı tarih ile yasal sürecin başladığı (risklerin "Tahsil Olunacak Alacaklar" hesabına aktarıldığı ) tarih, ikinci kez yapılanmaya giden firmalarda ise ikinci kez yapılanmaya gidildiği tarih arasındaki dönem "Yapılanma Dönemi" olarak kabul edilmiştir

Tablo-4 de modeldeki bağımsız değişkenlerin özet bilgileri yer almaktadır. Alacaklı bankaların katkısının ölçüldüğü değişkenler "Dış fonlara erișim yeteneği " başlığında ele alınmış ve "2" değișken ile temsil edilmiştir. Finansal sıkıntının şiddeti (sorun karmaşası) ise hem yapılanma öncesi hem de yapılanma dönemi ayrı ayrı ölçülmüş ve "4" değiş̧ken ile temsil edilmiştir.

Bağımsız değişkenlerin ölçümü aşağıda verilen formüle göre yapılmıştır.

\section{A11=YAPILANMA ÖNCESİ LIMIT DOLULUK ORANI= ORTALAMA RİSK/LİMIT}

\section{A12=YAPILANMADÖNEMİ LIMITT DOLULUK ORANI= ORTALAMA RİSK/LIMIT}

Firmaların toplam limit ve risk bilgileri TCMB da yayınlanmaktadır. Bu oranın hesaplanmasında, anlık verilerin yanıltıcı olabileceği düşünülerek, yapılanma öncesi ve yapılanma döneminde ortalama veriler alınmıştır.

$\mathrm{Bu}$ değişkenler firmanın krediye erişim olanaklarının bir ölçüsü olarak değerlendirilmektedir. A11-12 değişkenlerinin $1 \mathrm{e}$ yaklaşması firmanın fon sağlama imkanın azaldığını," 0" a yaklaşması ise banka sisteminden fon sağlama imkanının arttığını göstermektedir. Örneklemimizde, yapılanma öncesi yasal takip kaydı olan firmalar bulunmaktadır. Bu firmaların diğer bankalardaki limitlerinin dondurulmuş olabileceği değerlendirilerek, yapılanma öncesi ve sonrası limit risklerine bakılmıştır. Limit artışı yaşamayan, aynı zamanda risklerinde de azalma olan firmaların fon sağlama konusunda tam kısıtlı oldukları değerlendirilmiş ve bu firmalara orijinal oran yerine "1" oranı verilmiştir.

\section{A31 =YAPILANMA ÖNCESİ ORTALAMA ÖDENMEMIŞ FAİZ/ORTALAMA BANKA BORCU \\ A32 =YAPILANMA DÖNEMİ ORTALAMA ÖDENMEMIŞ FAİZ/ORTALAMA BANKA BORCU}

Firmanın ödeme performansının ölçümünde kullanan bu oranlar özellikle banka ilişkilerindeki sorun düzeyini betimleyen önemli değiş̧kenlerdir. Bankacılık sisteminde her üç ayda bir (mart-haziran-eylül-aralık ay sonunda) faiz tahakkuku yapılmakta ve kredili firmalarca ödenmektedir. Bu veriler her ay sonu düzenli olarak yayımlanmaktadır. Oranlar, firmanın ödemediği faiz tutarının aynı dönemdeki ortalama banka borcuna bölünmesi ile elde edilmiştir. Bu oranın artmasının sorun şiddetinin artması anlamına geleceği varsayılmıştır.

\section{A41 =YAPILANMA ÖNCESİ ÖDENMEMIŞ FAİZ DÖNEM SAYISI/TOPLAM DÖNEM SAYISI(12) A42=YAPILANMA DÖNEMI ÖDENMEMIŞ FAİZ DÖNEM SAYISI/TOPLAM DÖNEM SAYISI(12)}

A41, A42 değişkenleri, firmanın faiz ödememe listesinde yer alma sıklığını ölçmektedir. Örneğin, bir firma 12 aylık periyotta faiz ödememe listesinde $4 \mathrm{kez}$ yer almışsa, bu oran 4/12=0,25 olarak ölçülmüştür. Varsayım "Oran ne kadar yüksekse, finansal sıkıntı da o derece yüksektir" şeklinde yapılmıştır.

\section{ARAȘTIRMA BULGULARI}

Tablo: 5 de değişkenlerin başarılı ve başarısız gruplardaki ortalamaları yer almaktadır.

Tablo-5: Seçilmiş Bazı Değişkenlerin Başarılı-Başarısız Grup Ortalamaları

\begin{tabular}{|l|l|l|l|}
\hline $\mathrm{N}=109^{*}$ & & Ortalama & İstatistik \\
\hline $\begin{array}{l}\text { A11:YAPILANMA ÖNCESİ BANKA RİSKí/BANKA } \\
\text { LíMiTİ }\end{array}$ & 65-Başarısız & 0,8900 & $0,000^{*}$ \\
\hline & 44-Başarılı & 0,6409 & \\
\hline
\end{tabular}




\begin{tabular}{|c|c|c|c|}
\hline A12 YAPILANMA ÖNCESİ BANKA & 65-Başarısız & 0,9735 & $0,000^{*}$ \\
\hline & 44-Başarılı & 0,6103 & \\
\hline 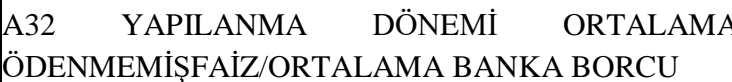 & 65-Başarısız & 0,0050 & $0,064 * *$ \\
\hline & 44-Başarılı & 0,0032 & \\
\hline
\end{tabular}

(*) 0,00 düzeyinde anlamlı (**) 0,10 düzeyinde anlamlı

44 Başarılı ve 65 Başarısız firma ile oluşturulan örneklemde A11-A12 değişkenlerinin ortalamaları istatistiksel açıdan başarılı ve başarısız firmalarda önemli ölçüde farklı çıkmışıı. Örneğin Yapılanma öncesi dönemde başarısız firmalarda limit doluluk oranı ortalaması (A11) 0,89 iken, başarılı firmalarda 0,64 dür. Daha açık bir anlatımla, başarılı borç yapılanması yapan firmaların bankalardaki kredi limitlerini kullanma bakımından, başarımız firmalara oranla daha iyi imkana sahip oldukları söylenebilir.

A32 değişkeninin başarılı ve başarısız firma ortalamaları da farklılık göstermektedir. Yani yapılanma döneminde başarısız firmalarda sorun karmaşası, başarılı firmalara oranla daha yüksek olmasına karşın, bu fark 0,064 güven düzeyinde anlamlidir.

\subsection{Başarılı -Başarısız Firmalarda Yapılanma Dönemi Değişimi}

Başarılı ve başarısız firmaların dış fonlara erişim yeteneği ve sorun karmaşasının yapılanma döneminde nasıl bir gelişim gösterdiklerini anlamak için 6 değişkenin önce ve sonra ortalamalarına bakılmıştır. Örneğin başarısız firmaların dış fonlara erişim yeteneğini ölçen Limit doluluk oranı yapılanma öncesi 0,89 iken yapılanma döneminde 0,9735 e yükselmiştir. Diğer bir anlatımla, başarısız firmaların dış fonlara erişim yeteneği yapılanma döneminde bir hayli azaldığı, neredeyse kredi kullanma imkanlarının olmadığı görülmemektedir. Bu bozulma istatiksel açıdan önemlidir.

Aynı şekilde, sorun karmaşasını ölçen Faiz Ödeme Performansı yapılanma öncesi dönemde 0,034 iken, yapılanma döneminde 0,051 seviyesine yükselmiştir. (0,12 güven seviyesinde anlamlı bir fark vardır)

Tablo 6: Başarısız Firmalarda Yapılanma Öncesi ve Yapılanma Dönemi Değişken Değerlerinin Değişimi

\begin{tabular}{|l|l|l|l|}
\hline DEĞISSKEN ADI & ORTALAMA & STAND.SAPM & STAN.HATA ORT \\
\hline A11-Y Öncesi Limit Doluluk Oranı & 0,8900 & 0,1435 & 0,0178 \\
\hline A12-Y Dönemi Limit Doluluk Oranı & 0,9735 & 0,0708 & 0,0087 \\
\hline A31-Y Öncesi Faiz Ödeme & 0,0034 & 0,0045 & 0,0005 \\
\hline A32-Y Dönemi Faiz Ödeme & 0,0051 & 0,0088 & 0,0011 \\
\hline A41-Y Öncesi Faiz Öd. Sayısı & 0,4897 & 0,3298 & 0,0409 \\
\hline
\end{tabular}




\begin{tabular}{|l|l|l|l|}
\hline A42-Y Dönemi Faiz Öd.Sayıs1 & 0,5674 & 0,4010 & 0,0497 \\
\hline EŞLER ARASI T STATISTIK SONUÇLARI & ORTALAMA & STND. SAPMA & $\begin{array}{l}\text { ISTATISTiK } \\
\text { Sig.(2.tailed) }\end{array}$ \\
\hline A11-A12 & $-0,0835$ & 0,1522 & $0,000 *$ \\
\hline A31-A32 & $-0,0016$ & 0,0082 & 0,121 \\
\hline A41-A42 & $-0,0776$ & 0,4798 & 0,196 \\
\hline
\end{tabular}

Tablo 7: Başarılı Firmalarda Yapılanma Öncesi ve Yapılanma Dönemi Değişken Değerlerinin Değişimi N=44 Başarılı Firma

\begin{tabular}{|c|c|c|c|}
\hline DEĞİŞKEN ADI & ORTALA MA & STAND. SAPMA & STAN. HATA ORT \\
\hline A11-Y Öncesi Limit Doluluk Oranı & 0,6409 & 0,2490 & 0,0375 \\
\hline $\begin{array}{l}\text { A12-Y Dönemi Limit Doluluk } \\
\text { Oran1 }\end{array}$ & 0,6103 & 0,2812 & 0,0423 \\
\hline A31-Y Öncesi Faiz Ödeme & 0,0032 & 0,0041 & 0,0006 \\
\hline A32-Y Dönemi Faiz Ödeme & 0,0032 & 0,0045 & 0,0006 \\
\hline A41-Y Öncesi Faiz Öd.Sayıs1 & 0,3935 & 0,3411 & 0,0514 \\
\hline A42-Y Dönemi Faiz Öd.Sayıs1 & 0,4498 & 0,3675 & 0,0554 \\
\hline EŞLER ARASI T STATISTIK SONUÇLARI & ORTALA MA & STAND. SAP MA & $\begin{array}{l}\text { İSTATİSTIK } \\
\text { Sig.(2.tailed) }\end{array}$ \\
\hline A11-A12 & 0,0305 & 0,2957 & 0,497 \\
\hline A31-A32 & 0,0000 & 0,0041 & 0,978 \\
\hline A41-A42 & 0,0562 & 0,3160 & 0,244 \\
\hline
\end{tabular}

$(*) 0,000$ güven düzeyinde anlamlıdır.

Genel olarak değerlendirildiğinde, başarısız 65 firmanın yapılanma döneminde dış fonlara erişim bakımından durumunun kısıtlandığı ( Yapılanma öncesi oranı 0,89, yapılanma dönemi oranı 0,97), finansal sıkıntı şiddetinin de nispeten arttığı (yapılanma öncesi oranı 0,0050, yapılanma dönemi oranı 0,0032dür.0,064 düzeyinde istatistiksel olarak anlamlıdır) anlaşılmaktadır.

Başarılı 44 firmada, yapılanma öncesi ve yapılanma döneminde, dış fonlara erişim ve sıkıntı şiddeti bakımından istatistiksel olarak fark bulunamamıştır.

\subsection{Lojistik Regresyon Modeli}

Önceki bölümlerde ölçümleri ve ilişkilerin yönleri verilen değişkenlere göre Lojistik regresyon modeli; 
$\mathrm{L}=\mathrm{bo}+\mathrm{b} 1 \mathrm{~A} 11+\mathrm{b} 2 \mathrm{~A} 12+\mathrm{b} 3 \mathrm{~A} 31+\mathrm{b} 4 \mathrm{~A} 32+\mathrm{b} 5 \mathrm{~A} 41+\mathrm{b} 6 \mathrm{~A} 42+\mathrm{e}$ dir.

A11 ve A12 değişkenleri sorunlu firmaların Bankalardaki limit doluluk oranlarını göstermektedir. Bu oranın düşük olması firmaların kredi erişiminin daha kolay olduğuna işaret etmektedir. Kolay kredi erişimi olan firmaların, daha likit oldukları ve dolayısıyla başarılı borç yapılanması yapma ihtimallerinin daha yüksek olduğu varsayılmıştır. İlişki ters yönlüdür.

A31,A32,A41,A42 değişkenleri finansal sıkıntının şiddetini ölçmektedir. Bu değişkenlerin değerleri artıkça başarılı borç yapılanması ihtimalinin azalacağı varsayılmıştır. Bu değişken grubunda da ilişki ters yönlüdür.

Tablo-8 de Modelin özet sonuçları verilmektedir.

Tablo-8: Lojistik Regresyon Modeli Özet Sonuçlar

\begin{tabular}{|l|l|l|}
\hline Değişken Adı & Değişken katsayısı & istatistik \\
\hline A11-Yapılanma Öncesi Banka & $-6,889$ & 0,002 \\
\hline A12-Yapılanma Dönemi Banka & $-14,993$ & 0,000 \\
\hline Sabit & 17,064 & 0,000 \\
\hline & & Öngörü Yüzdesi(\%) \\
\hline Öngörü & Başarılı & 96,9 \\
\hline & Başarısız & 81,8 \\
\hline & Toplam & 90,8 \\
\hline Cut Value & Oran & \\
\hline
\end{tabular}

6 değişkenli lojistik regresyon modeline A11 ve A12 değişkenleri girmiştir. A11 değişkeni yapılanma öncesi Limit Doluluk Oranı, A12 değişkeni ise yapılanma dönemi limit doluluk oranını ifade etmektedir. Finansal açıdan sıkıntılı firmaların Bankacılık sisteminden fon sağlama imkanlarının artmasının başarılı borç yapılanmasında önemli olduğu bu sonuçlara bakılarak söylenebilir. Değişken katsayılarına bakıldığında, yapılanma döneminde bu katkının daha da önemli olduğu görülmektedir.

Modelin doğru sınıflama yüzdesi ise başarılı firmalarda \% 96,9, başarısız firmalarda $\% 81,8$ ve ortalamada $\% 90,8$ olarak oldukça yüksektir. Diğer bir anlatımla, modelin gerçekte başarılı borç yapılandırması yapmış bir firmayı doğru tahmin etme ihtimali \% 96,7, başarısız bir firmayı doğru tahmin etme ihtimali de \%81,8 dir.

\section{SONUÇ}

Finansal başarısızlık çok genel anlamı ile finansal yükümlülüklerin yerine getirilememesi ile ilgili bir kavramdır. Finansal başarısızlık ile baş etme yolunda önemli bir aksiyon olarak, borçların yeniden yapılandırılması, firmanın nakit akışındaki uyumsuzluğun, firmayı yaptırımlardan korumak amacıyla yeni sözleşme koşullarına bağlanarak giderilmesi anlamına 
gelmektedir. Aslında borç yapılanmasıyla, hayatta kalma şansı olan firmaların yaşamına devam etmesine olanak tanınmaktadır. Hangi firmaların hangi koşullarda bu başarıya ulaşacağı sorunu makro açıdan da çok önemlidir.

Çalışmamızda, başarılı borç yapılanmasında dış fonlara erişim yeteneği ile finansal sıkıntı şiddetinin etkisi irdelenmiştir.

Yazında konu ile ilgili yapılan çalışmalarda bankaların yapılanma sürecine olumlu katkısının başarılı borç yapılanmasında önemli olduğu yönünde tespitler bulunmaktadır. Benzer şekilde finansal sıkıntının şiddeti arttıkça özel görüşme yoluyla yoluyla borç yapılanmasının güçleşeceği konusunda da araştırmalar da bulunmaktadır.

$\mathrm{Bu}$ kuramsal çerçevede, başarılı borç yapılanması, firmaların maruz kaldıkları finansal sıkıntı şiddeti ile negatif, banka fonlarına erişim yeteneği ile pozitif yönlü bir ilişkiye sahiptir.

Bu varsayımları test etmek amacıyla, bir kamu bankasında 44' ü başarılı, 65'1 başarısız borç yapılanması yapmış 109 firmalı bir örneklem oluşturulmuştur. Geliştirdiğimiz Lojistik Regresyon modelinde hem yapılanma öncesinde, hem de yapılanma döneminde Bankacılık sisteminden sağlanan fonlara erişim yeteneği önemli bir değişken olarak karşımıza çıkmıștır. Finansal sıkıntı şiddeti, başarısız firmalarda artmasına rağmen modele açıklayıcı bir değişken olarak girememiştir. Bu açıdan, kuramsal beklentiye uygun olarak, bankanın önemli bir işlev gördüğü söylenebilir.

Sonuç olarak, başarısız yapılanma yapan firmalarda, Bankanın olumsuz etkisi daha belirgin bir biçimde gözlenmektedir. Diğer bir anlatınla, bankanın kaynak sağlamaya yardımcı olmadığı durumlarda, başarılı borç yapılanması oldukça zor gözükmektedir. Örneklemimiz daha çok küçük ve orta ölçekli işletmelerden oluşmaktadır. Bu türden firmaların sermaye yapısını kolayca değiştirebilecek araçlardan yoksun olduğu göz önüne alındığında, borçlanmasını sürdürebilecek dış kaynak erişimine açık olduğu ölçüde, başarılı bir borç yapılanma şansının olduğu söylenebilir.

Alacaklı bankalar açısından, böyle bir profili olan ve bu profili sürdürebilecek firmaların başarılı borç yapılanma şansının yüksek olduğu bilgisi pratik bakımdan anlamlı olabilir. Diğer yandan, makro düzeyde düşük likidite dönemlerinde, bankaların bu tür firmalara destek verememesinin, daha kitlesel sorunlara yol açabileceği göz önünde bulundurulmalıdır.

\section{KAYNAKÇA}

ASQUIT, P., GERTNER, R., SCHARFSTEIN, D. (1991). Anatomy of Financial Distress: An Examination of Junk Issuers,NBER Working Paper 3942,papers.ssrn.com/sol13/papers.cfm?abstract $=227358$

BROWN, D., JAMES,C., MOORADIAN,R. (1993). The Information content of Restructuring İnvolving Public and Private dept Claims. Journal of Financial. 33: 39-118

FRANKS, J., TOROUS,W.(1994). A Comparison of Financial Recontracting in Distressed Exchanges And Chapter 11 eorganization, Journal of Financial Economicis:35, S.349-370

GERTNER, R., SCHARFSTEIN, D. (1991). A Theory of Workouts and the effects of Reorganization Law. The journal of inance.46 (4) : $1189-1222$

GILSON, C., KOSE,J., LANG.L. (1990). Troubled Dept Restructuring An Emprical Study of Private Reorganization Of firms in default. Journal of Financial Economics. (27) :315-353

GíLSON, C. (1997). Transaction Costs and Capital Structure Choice:Evidence from Financially Distressed Firms . The Journal of Finance.52(1):161-196)

HOTCHKISS, E., KOSE, J., MOORADIAN, R., THORNBORN, K. (2008). Bankruptcy and The Resolution of Financial Disress, Handbook of Emprical Corporate,Volume 2,Edited by B.EspenEckbo, Papers. ssrn. com/ sol3/ papers. cfm? Abstract _ id=1086942

JAMES, C.(1996). Bank Dept Restructuring and the Composition of Exchange Offers in Financial Distress" The Journal of Finance.51 (2): 711-727

MOORADIAN, R. (1994). The Effect of bankruptcy Protection on Investment:Chapter 11 as a Screening Device.The Journal of Finance.49(3) : 1403-1430 
OFEK, E. (1993). Capital Structure and Firm Response to poor Performance An Emprical Analysis "Journal of Financial Economics.34: 3-30 